\title{
CONSTRUÇÃO COLABORATIVA DE MATERIAL EDUCATIVO DIGITAL PARA LIDAR COM O PROCESSO DE MORTE E MORRER DURANTE A GRADUAÇÃO EM ENFERMAGEM
}

\author{
Helen Chaves Pereira ${ }^{1}$ \\ Aretusa Thame de Morais Santos ${ }^{1}$ \\ Alfredo Almeida Pina-Oliveira ${ }^{2}$ \\ ${ }^{1}$ Enfermeira formada pela Universidade Guarulhos \\ ${ }^{2}$ Professor Doutor em Enfermagem da Universidade Guarulhos
}

INTRODUÇÃO: O processo de morte e morrer contempla aspectos físicos, sociais, culturais e espirituais, que exigem mudanças nos modelos de cuidar realizado pelos diferentes profissionais de saúde. Desenvolver competências para cuidar do paciente que vivencia a finitude pode contribuir para a futura inserção profissional dos acadêmicos de Enfermagem. OBJETIVO: apresentar um material educativo digital (MED) para lidar com o processo de morte e morrer durante a formação em graduação de enfermagem. MÉTODO: Tratouse de uma pesquisa-ação realizada em grupo fechado no Facebook® e fundamentada na Pedagogia Crítica de Paulo Freire. Participaram seis acadêmicos de graduação em enfermagem, do oitavo período matutino da Universidade Guarulhos. No período de março a abril de 2018, foram realizados Círculos de Cultura Virtuais (CCV) com base nas seguintes perguntas norteadoras: "Como vocês se imaginam cuidando de um ser humano no processo de morte e morrer?" E "Quais competências vocês julgam necessárias para desempenhar tal prática?". Empregou-se a análise temática de Bardin nos registros das interações entre os participantes no Facebook $\circledast$ e, complementarmente, utilizou-se o software WebQDA 3.0 para organizar e analisar o corpus do estudo. Para a construção do MED foi escolhida a ferramenta digital gratuita Adobe Spark $\AA^{\circledR}$ e os participantes reavaliaram a página on-line construída pelo grupo de pesquisadores a fim de realizar considerações e modificações. A presente pesquisa foi aprovada pelo Comitê de Ética em Pesquisa da Universidade Guarulhos sob o parecer 꿀 2.485.315. RESULTADOS: emergiram duas categorias: "A complexidade do cuidado no processo de morte e morrer" e "O enfrentamento pessoal relacionado ao cuidar na finitude da vida" que permitiram delinear os conteúdos e recursos para construir o protótipo de MED "Primeiros passos para lidar com o processo de 
morte e morrer" disponível no link https://adobe.ly/2GUbwWY. CONSIDERAÇÕES FINAIS: $O$ processo colaborativo resultou em uma ferramenta inovadora e relevante para subsidiar o desenvolvimento de competências para lidar com o processo de morte e morrer desde a formação inicial na graduação em enfermagem.

Palavras-chave: Tecnologia educacional. Estudantes de enfermagem. Atitude frente à morte. Educação em enfermagem. Pesquisa qualitativa. 